Journal of Machine Engineering, 2021, Vol. 21, No. 1, 5-21

ISSN 1895-7595 (Print) ISSN 2391-8071 (Online)

Received: 08 January 2021 / Accepted: 16 March 2021 / Published online: 29 March 2021

condition monitoring,

sensor integration,

Industry 4.0

Friedrich BLEICHER ${ }^{1 *}$, Christoph RAMSAUER ${ }^{1}$, Martin LEONHARTSBERGER ${ }^{1}$, Matthias LAMPRECHT ${ }^{1}$, Philipp STADLER ${ }^{1}$

Dominik STRASSER ${ }^{1}$, Clemens WIEDERMANN ${ }^{1}$

\title{
TOOLING SYSTEMS WITH INTEGRATED SENSORS ENABLING DATA BASED PROCESS OPTIMIZATION
}

\begin{abstract}
Sensor integration into machining equipment has become an important factor for gaining deep process insights mainly driven by increasingly smaller and cheaper sensors and transmitters. Due to advances in microelectronics and communication technology, a broader field of applications in production processes and machine tools can be addressed using sensing devices and their implementation potentials. Ensuring a sensitive but robust data stream from close to the actual process allows not only reliable monitoring but also process and quality control based on sensor information. This paper provides an overview of the utilization of sensor data for the purpose of condition monitoring, model fitting and real-time control coping with stochastic effects. Examples of sensor integration in fields of injection molding, roll forming and heavy-duty milling comprise the state of the art of sensor implementation, data evaluation and possible feedback loops in the respective application scenarios.
\end{abstract}

\section{INTRODUCTION}

Motivated by the aim of achieving high quality in processes and parts, reduction of setup time and process understanding, sensor integration is becoming increasingly important (see [1]). This paper shows sophisticated possibilities for sensor-equipped processes and summarizes the state of the art of process monitoring and control briefly.

Sensors on semiconductor basis, piezo-resistive strain gauges and piezoelectric sensors were developed with the spread of the silicon technology in the 1970s. Since then, innovations like "system on chip" (SoC) and integrated MEMS (Micro Electro Mechanical Systems) together with further miniaturization, increasing intelligence and decreasing prices of such components led to today's sensor technology [2]. The application areas for tool system integrated sensors are subject to competing requirements for time response or location of sensors. The used sensors are usually selected with respect to their sensitivity, reliability, costs and the measured parameters that are fundamental to the process being observed. As

\footnotetext{
${ }^{1}$ IFT - Institute for Production Engineering and Photonic Technologies, TU Wien, Austria

*E-Mail: bleicher@ift.at https://doi.org/10.36897/jme/134244
} 
modern manufacturing processes become more and more complex, the benefits of enhanced sensor-use increased. Tooling applications including sensor systems which are inexpensive, robust for the use in the processing environment and easy to use are required. In addition, there must be an overriding advantage for the user that is in proportion to the costs incurred by the additional sensors. Jemielniak states in [3] that also user friendliness and reliability are required for industrially applicable systems.

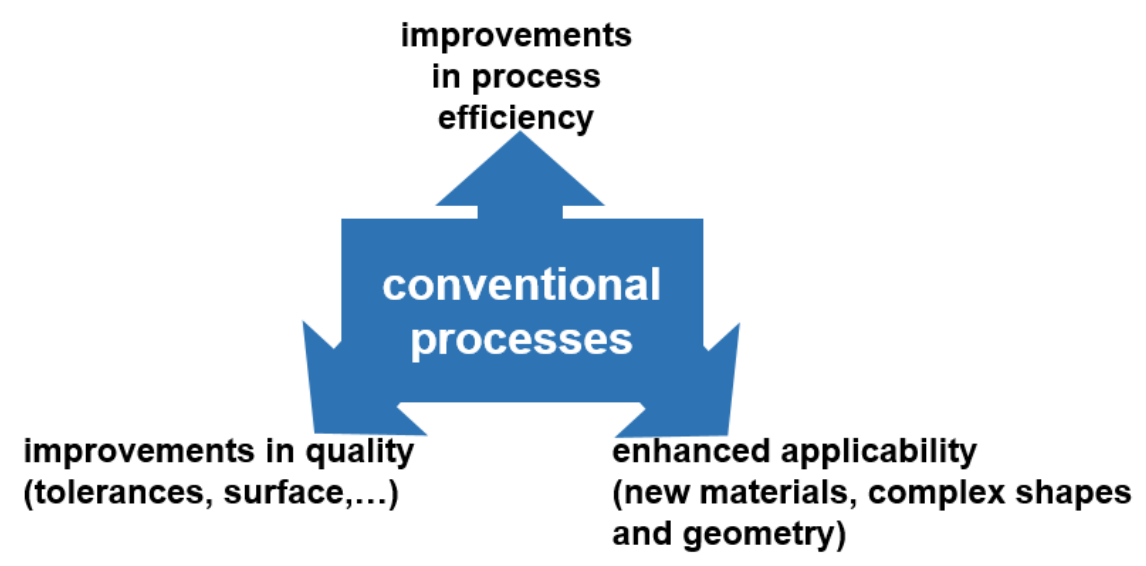

Fig. 1. Overcoming limits of conventional processes

Leading towards improvements in process efficiency and quality, as well as providing enhanced applicability requires overcoming existing limits of conventional processes, as summarized in Fig 1. In particular, stochastic phenomena such as geometry and shape deviations of raw parts due to preliminary processes like casting, forming or even 3D-printing together with changing material properties of raw material batches take significant influence in industrial process application. In conventional processes, these aspects often cause a conservative setting of process parameters and thus reduce the economic efficiency. A reasonable approach to meet modern requirements in manufacturing processes and to handle stochastically occurring events is the integration of sensors for monitoring and control purposes [3, 4]. However, this allows measurement and direct optimization of the conventional production process, monitoring, adaptive process control and fitting of model parameters for the setup and validation from simulations e.g. digital twins and CPPS (Cyber Physical Production Systems) [5, 6].

One common feature of all of the following sensor integration scenarios is the location of the sensor in the nearest part of the process being not a consumable or the product itself. The long lifespan of a cavity mold, a roll forming stand and a tool holder allows an important decrease of costs of sensitization.

Ensuring part quality in highly repetitive processes, like injection molding, is enabled by detecting temperature and pressure [7] as well as heat flux [8] in the cavities. Furthermore, this data can be used to enable feature learning in the course of data-based process monitoring [9]. In [10], Monostori states another possibility for modeling and monitoring of manufacturing processes, which can be realized by combining sensor integration with artificial neural networks techniques. 
Gaining deep insight about complex forming processes via sensor integration is highlighted by roll forming, where a different approach arises. An increased repeatability, a reduction of setup time and constant process parameters can be achieved by sensor integration into multi-step forming processes like roll forming. Like in many other application scenarios, contact normal forces in the individual forming steps [11] and the drive torques applied by the drive of such plants [12] are monitored. The manufactured product is mainly controlled by scanning the generated geometry [13]. The acquired measurement data can in turn be used to deepen the understanding of the entire roll forming process [14] and to derive optimizations concerning the tool geometry [15]. By correctly interpreting this data, adjusttments of the roll forming line can be made to ensure the desired high-quality output of the product. Furthermore, there are current studies dealing with set up times [16] and the validation of simulation models of the process $[17,18]$.

Process control based on sensor integration in machining processes finally shows the potential of all three aspects of Fig 1. For instance, sensor integration in positions like in the work piece or e.g. in milling tools [19] lead to a new sensor for each produced part or substituted tool. Thus, the measurement of vibrations [20,21] and accelerations [22] for the detection of unfavorable machining- or process conditions, tool wear or even a crash become possible. Another advantage of sensor integration into tools can be found in a rather direct transmission behavior with little influence of other machine parts in the vicinity of the process compared to other methods like monitoring the motor current or the acoustic emission characteristics of the process $[23,24]$. At locations rather remote to the actual process, thermally induced changes in machine behavior [25], mechanical coupling and external disturbances easily play a major role when process conditions are measured.

The extensive use of sensor information enables significant perspectives in the development of computer science, information and communication technologies in manufacturing systems. Monostori in [26] states, that collaborating computational entities which are in intensive connection with the production systems represent CPPS. The system structure of tools with integrated sensors for data acquisition close to the process provides information preferably in real-time and uses data-accessing and data-processing services available on both, internal information platforms or e.g. via web by the use of cloud systems. Four strategies (not exclusive) can be envisioned for the use of this information:

- process near data acquisition, which will be used for process optimization,

- establishing a knowledge base by capturing and monitoring of the empirical process effects for subsequent optimization or new process design,

- direct measurements from tool integrated sensors for feedback to controllers enabling process adaption by heuristic or physic-based rules,

- information feedback and validation of process models, that allow the performance to be predicted.

For further elaboration, a comprehensive overview of sensor technologies, of signal processing and decision-making strategies is given by Teti et al in [27]. Overall serial production like injection molding, complex multistage processes like roll forming and batch-size-1 processes with large impact of stochastic effects, sensor integration has a large potential enabling data-based process optimization. 


\section{UTILIZING SENSOR DATA}

Referring to the above mentioned four aspects of sensor information utilization, one option is the use of gained data from different sources for monitoring the condition of the process, the tool and the work piece. Due to these efforts, it is possible to achieve an increase in interesting aspects for quality control, predictive maintenance and cost reduction.

Firstly, sensing the process' condition can lead to real time evaluated process monitoring, causing alerts or drawing graphs in the near surroundings of the machine tool user like in Fig. 2A. Besides sensor information for tool condition monitoring like in [1] or additionally in [3, 4, 28], data of the NC can be used as additional information for anomaly detection [29]. These kinds of evaluation are often based on key figures and fixed rule engines to provide a real-time statement for online and inline analyses. Data visualization can be provided by monitors and cellphone apps as well [30].

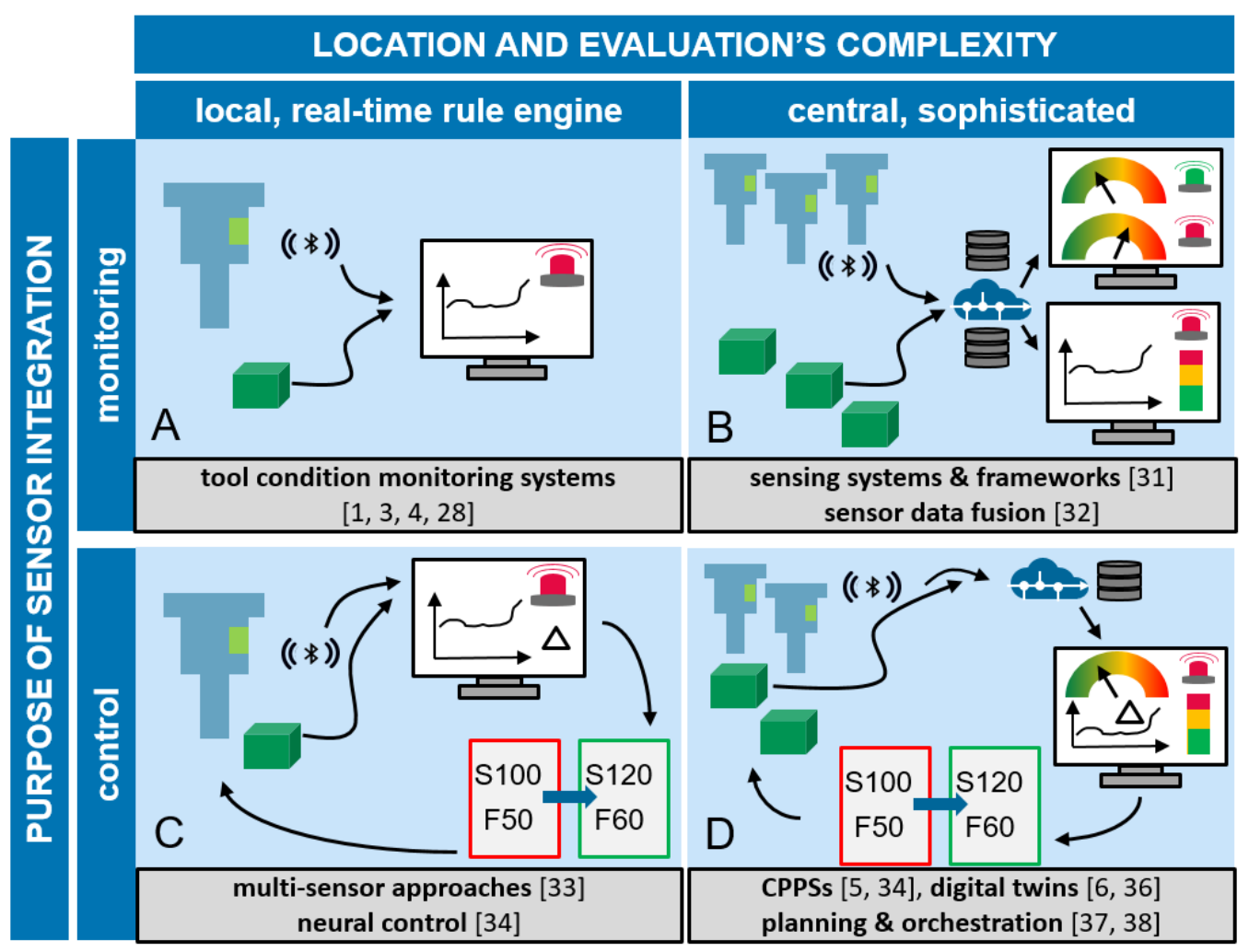

Fig. 2. Overview of benefits by sensor integration

Secondly, sensor data can be pushed up in a higher level of hierarchy to support a holistic surveillance of several sources within one or several machine tools at a production site. Like in Fig. 2B, data can be accumulated via networks or cloud services [32, 33]. Merging different sensors' signals and correlating signal characteristics to tool wear and work piece quality can be used for training algorithms, as shown by Möhring in [39]. With high computational power for teaching and training, artificial intelligence and machine learning 
can be addressed [40]. Thus, simple rule engines for time-sensitive systems (Fig. 2A \& C) can be developed and adjusted out of simulations or models of high complexity. Moreover, cost benefits can be achieved by in-process monitoring with real-time capabilities of signal processing and a feedback loop enabling a reduction of scrap parts by direct interaction and parameter adaption.

Similar to these levels of monitoring strategies, process control via feedback loops can be accomplished. A rather simple rule engine, for instance running on an industrial PC [41], and local countermeasures are needed for a real-time process control, like in Fig. 2C. Once again, various data sources connected via networks and databases can be utilized for a sophisticated evaluation to adjust process parameters (Fig. 2D). In this context, aspects of data storage, administration and information strategies require interdisciplinary cooperation with fields of computer science. In this regard, the European initiative of GAIA$\mathrm{X}$ sets a new framework and standards. Rather long-term feedback loops can be set up, also involving production planning and CAM (computer aided manufacturing). Nevertheless, in terms of digital twins, complex sensor integrated feedback loops are getting faster and suitable for on-line measurement [42] and aiming for real-time adaption [43].

\section{USE-CASE INJECTION MOLDING}

Injection molding is an important process for mass production of plastic parts with high demands on their quality, especially dimensional accuracy and surface, as well as complex geometries. A sensor-equipped tool provides methods for process monitoring to detect insufficient quality of produced parts like surface defects. To achieve high process stability consistently, the cycles of the injection molding process have to be as identical as possible. An adequate setup of the machine and process parameters can be derived via identification from process monitoring $[44,45]$.

In recent years, various approaches have been presented and introduced to monitor process parameters of injection molding in real-time and furthermore to reduce common quality defects such as warpage or shrinkage [46-49]. Many sensor-supported monitoring systems for measuring pressure and temperature are used for process monitoring of injection molding in order to obtain an insight into the injection molding process [50,51]. Furthermore, there is a lot of potential for developing a control system as injection molding machines are able to learn the operations supported by machine learning and big data $[52,53]$.

\subsection{SENSOR INTEGRATION IN MOLDS}

Cavity pressure measurement provides precise information about the injection process and is a widely acknowledged basis [54, 55, 56] for process monitoring, controlling and indicating errors of injection molding processes. As shown in a previous study dealing with the development of smart monitoring [57], cavity pressure sensors and temperature sensors are used to derive the optimal process window to reduce the number of scrap parts. 
A combined pressure and temperature sensor for mold and polymer, e.g. a triple-combined FOS-sensor of FOS-Messtechnik $\mathrm{GmbH}$, suits well for the simultaneous measurement of cavity pressure and melting temperature, which subsequently can be used for calculating process-specific rheological properties [58]. The identification of correlation between process parameters of injection molding and final part quality, classified on visual inspection of the specimens and their weight, is shown in [59]. Another study in [60] identified common process parameters such as cavity pressure and switching point to holding pressure, which are then used to forecast unplanned machine downtime. Further research in [61] shows that varying process parameter settings, like switching point, can be reflected in cavity pressure profiles. The following example focuses on the measurement of cavity pressure and the switching point between injection and holding pressure, which is visible in the pressure curve.

\subsection{EXPERIMENTAL SETUP FOR MONITORING CAVITY PRESSURE}

The data used in this setup was acquired from a triple-combined FOS-sensor, type MTPS 408-IR-BTS-XSR, installed in the mold cavity of an "Engel ES600/100 HLSEL" injection molding machine with an EC100/CC100 control unit. The configuration of the used sensor and the structure of cavity are illustrated in Fig. 3. The focused part is an ISO 20753 multipurpose test specimen type A1 [62] and the used material is Novodur HH-112 Acrylonitrile Butadiene Styrene (ABS). The experiments depict differences in pressure and part quality between three different settings of pressure properties. The switching point defines where low pressure, used for filling the mold, turns to high pressure for finalizing the molded part.
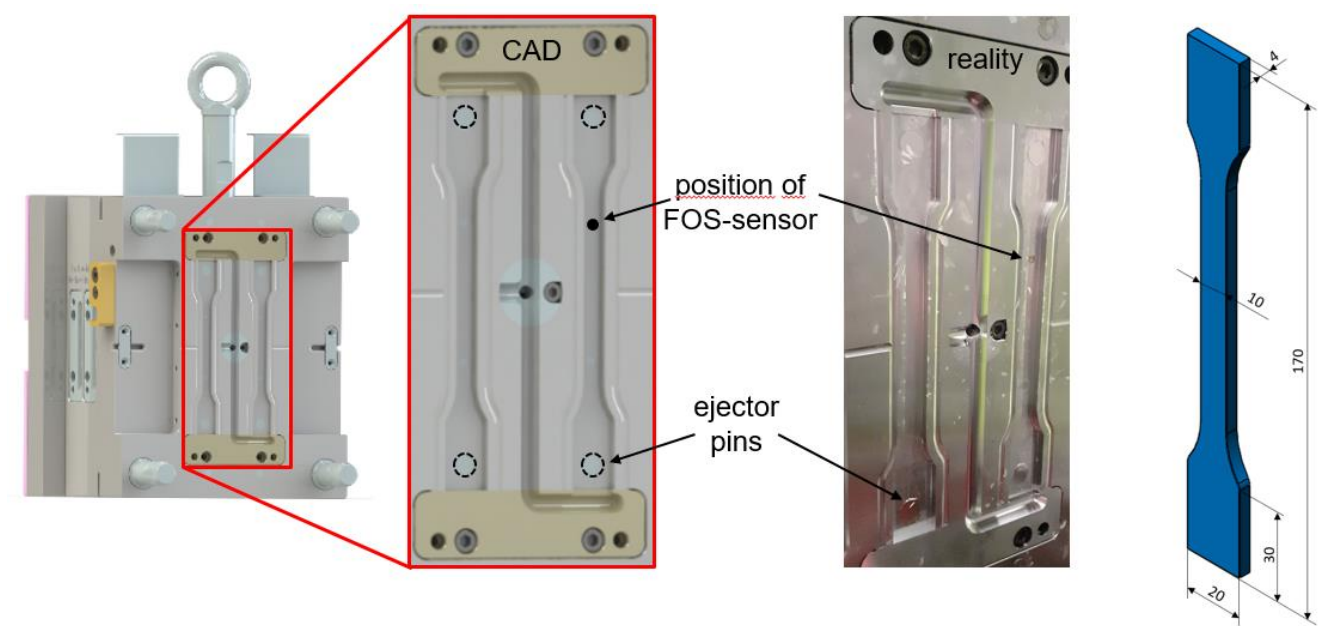

Fig. 3. CAD model, real mold with embedded sensors and CAD model of test specimen

Each single switching point setting was used to produce 5 individual parts, leading to a total of 15 parts and the corresponding sensor data. While all three settings show similar tensile strength, the varying quality features for classifying differences are the mass of the 
produced test specimen and the degree of filling the edges of the cavity. Fig. 4 shows the experimental results for cavity pressure regarding different switching points.

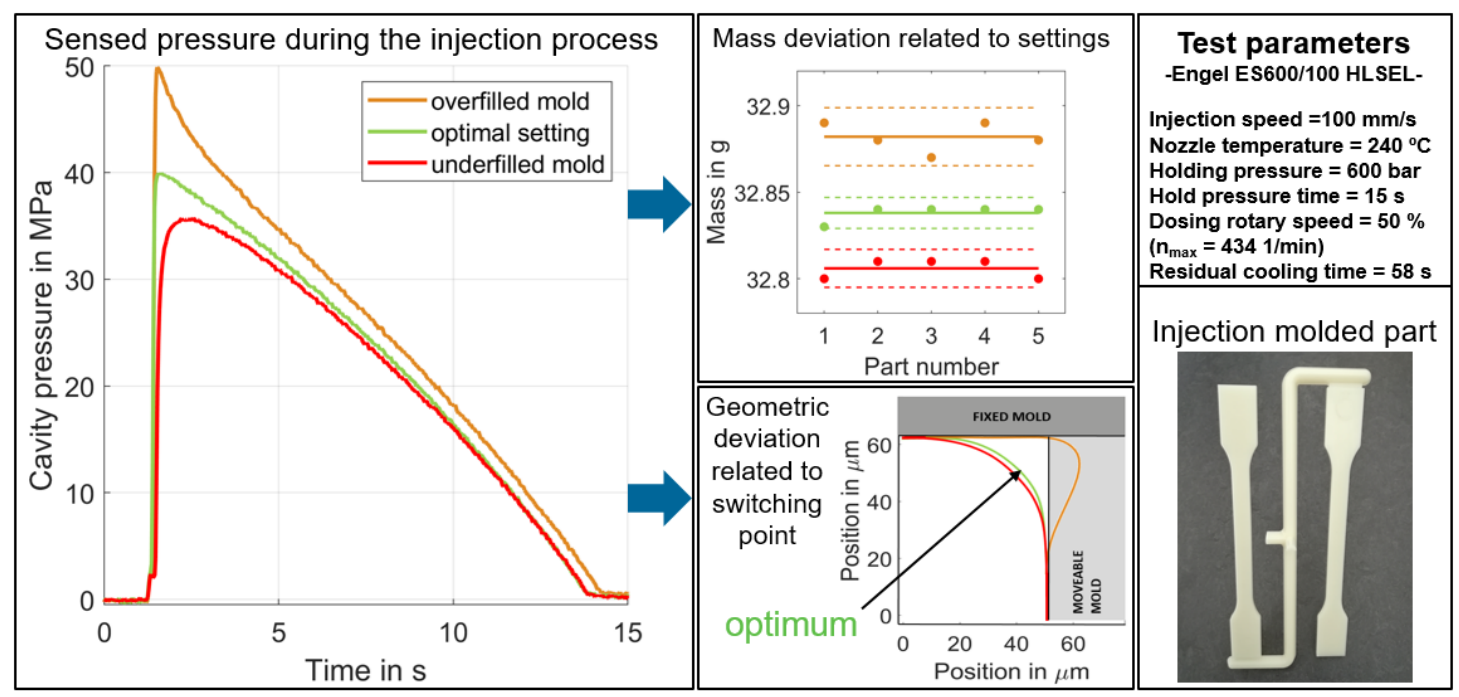

Fig. 4. Pressure during the injection molding process and resulting deviation of mass related to switching point for the given test parameters

By comparing the patterns of the cavity pressure, it becomes evident, that each switching point results in a different pressure profile. The red cavity pressure profile in Fig. 4 (left) shows an injection pressure that is insufficient to compress the melted polymer and fill the provided cavity, resulting in a short shot, sink mark and warpage. In addition, the edges are not filled sharply. As depicted by the orange curve in Fig 4, the pressure can also indicate overfilling of the cavity, leading to higher mass of the work pieces. An adequately set switching point leads to the aspired pressure, so that the melted polymer accomplishes a complete filling of the cavity without overfilling, but also generates sufficient compression of the melted polymer in the cavity. The characteristic cavity pressure profile of a properly adapted switching point illustrates the green line in Fig. 4 (left). Process monitoring and the potential of combined autonomous process controlling are important aspects to keep the quality of the produced parts constant and to avoid severe damage to the mold. Forecasting, stabilizing and assuring quality in mass production processes provide economic advantages based on sensor integration.

\section{USE-CASE ROLL FORMING}

The second example of sensor integration in tooling systems is a forming process. In many metal forming processes, intelligent tools with integrated sensors are used to monitor and control the process. Yang [63] gives an overview of smart metal forming by using dieembedded sensors. Kim [64] used bolt type piezo-sensors to measure the load on the die, Hagino [65] used ultrasonic sensors to measure contact states between the work pieces and 
the die. Yang [66] further used acoustic emission sensors for the detection of friction sources. In the following, the faced problems and chances through sensor integration in forming processes are discussed on the chosen example of roll forming. This process is a continuous, incremental forming process where a sheet of metal is formed through pairs of contoured rolls, which are aligned on shafts. The outer contour of these tools defines the shape of the produced profile. Up to 60 of these pairs of forming rolls are used to form the desired profile on a conventional roll forming line. Additionally, processes like welding, punching etc. allow to form very complex profile geometries used in a broad field of applications like building, agriculture, furniture etc. Roll forming is a process suitable for large quantities due to high production speeds. Therefore, these application scenarios provide great potential to overcome limits of non-sensorized settings.

One of the challenges of the roll forming process compared to others are the high changeover times of roll forming lines for new work piece geometries and even for followup productions. As the market demands higher flexibility and therefore smaller batch sizes, high number of changeover events and the resulting time efforts lead to reduced economic efficiency. The high set-up times are mainly caused by the geometry adjustments which are necessary on the line for each forming stage to produce a profile which fulfills the tolerance requirements. There are many ways, how a roll forming line can be tuned to reach the desired profile geometry even with the identical tool set. This means there is no "right" or "wrong" set of machine parameters, which makes the detection of process failure based on in-process data even more challenging. The detection of success and failure produced by a parameter set is a crucial factor to rate the setup and can currently only be rated by the output geometry. There are a few approaches how to reduce these problems. Müller [67], Traub et al. [68], Lindgren [69], Leonhartsberger [70], Lamprecht [71] and a few others, already showed sensor integration into roll forming stands on a laboratory scale to investigate the process or to validate simulations. According to these publications, the integration of load cells into roll forming stands, to measure occurring contact normal forces is an efficient solution to monitor the process. Traub et al. in [72] even showed the integration of a sensory feather key to measure the torques on different tools. Another possibility to measure occurring load-levels via sensing bolts is demonstrated by Groche and Brenneis in [73]. However, most of these sensor integrations are used for research purposes. Commonly, the integration of such sensor equipment is not applicable in the industry in terms of costs, simply because an enormous number of roll forming stands is used in practise.

In the last decade, finite element (FE) simulations have become the state of the art instrument when the process of roll forming is studied. In most finite element models, the rolls are considered to be rigid bodies [74-79]. As a consequence, the emerging forming forces are independent of the compliance of the tools. The simulations can be used to identify the needed force levels to shape the bend radii of the desired profile correctly. The adjustments on a roll forming mill to get the desired shape are still carried out manually and directly in the arrangement on the roll forming line. These processes, needed to meet the given tolerance fields on the machine, are very time-consuming. Traub et al. in [68] showed a way to reduce the setup times for recurring profile shape/material combinations by monitoring the occurring forces and torques and assisting the operator to adjust the line until all monitored quantities are near the known reference (recorded before). 
In contrast, this study focuses on the tuning process for "correct" adjustment of the rolling stands before production, ex ante, by using data from simulations or geometric features recorded from prior productions. Thereby no in-process sensors need to be used. The performance of the process is judged by installed sensors, which are just needed for validation.

\subsection{EXAMPLE SETUP AND METHODOLOGY OF FORCE SENSING IN ROLL FORMING}

In the course of these investigations, experiments with four forming passes were carried out to produce an unsymmetrical profile shown in Fig. 5 on the right side. All forming stages are equipped with force sensors (Kistler 9333A) integrated in the operator-side as well as the drive-side forming stands (Fig. 5 left). For detecting the output geometry, an automatic and laser-triangulation based scanning station (equipped with two Keyence LJ-V7200 - 2D Laser Profilers) is used to gather the 3D-data of every single profile during production.

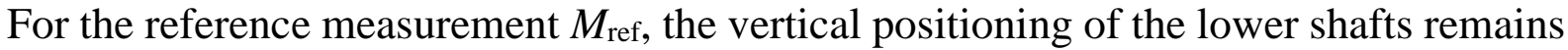
unchanged, but the upper shaft is lowered until the load level of the corresponding simulation of the forming process with rigid and fixed forming rolls are established. This adjustment is then assessed by the output geometry of the profile, which is studied in detail to ensure its functionality. It could be revealed, that the force levels retrieved by simulations applied to the real process lead to sufficient profile geometry and a stable process. Further on, the measurement $M_{\text {ref }}$ serves as the reference experiment to evaluate the functionality of the sensor assisted set-up process in comparison to the conventional. To validate the performance of the developed setup process, the profile geometry and arising forces are compared to the reproduction realized by different machine operators. The operators find a machine totally maladjusted and have to readjust it to generate the desired profile shape.

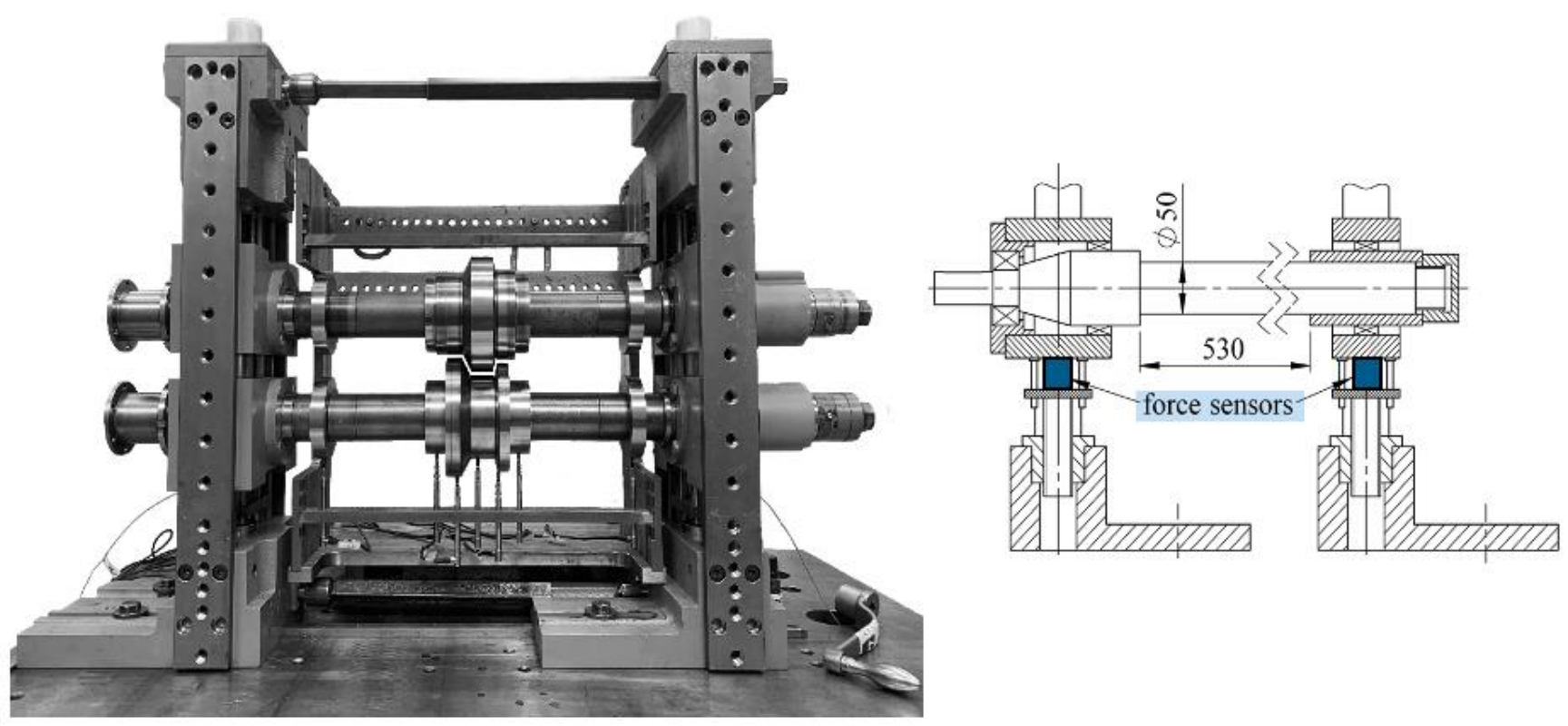

Fig. 5. Experimental setup and sensor integration 


\subsection{RESULTS OF SENSOR EQUIPPED ROLL FORMING PROCESS}

Figure 6 shows the recorded contact normal forces in the forming stands and two corresponding characteristics of the output profile geometry derived from the 3D-data gathered by the mentioned scanning system. The different colors represent the forces recorded in the different forming stages of the profile. The grouped data is always one attempt to reproduce the reference state " $M_{\mathrm{ref}}$ ". The bar groups $\mathrm{M}_{\mathrm{O} 1}$ to $\mathrm{M}_{\mathrm{O} 4}$ show the reproduction of the machine operators by the conventional process without the usage of sensors. The other bar groups show the reproduction of the geometric characteristics recorded in $M_{\text {ref }}$ by the described sensor assisted setup process.
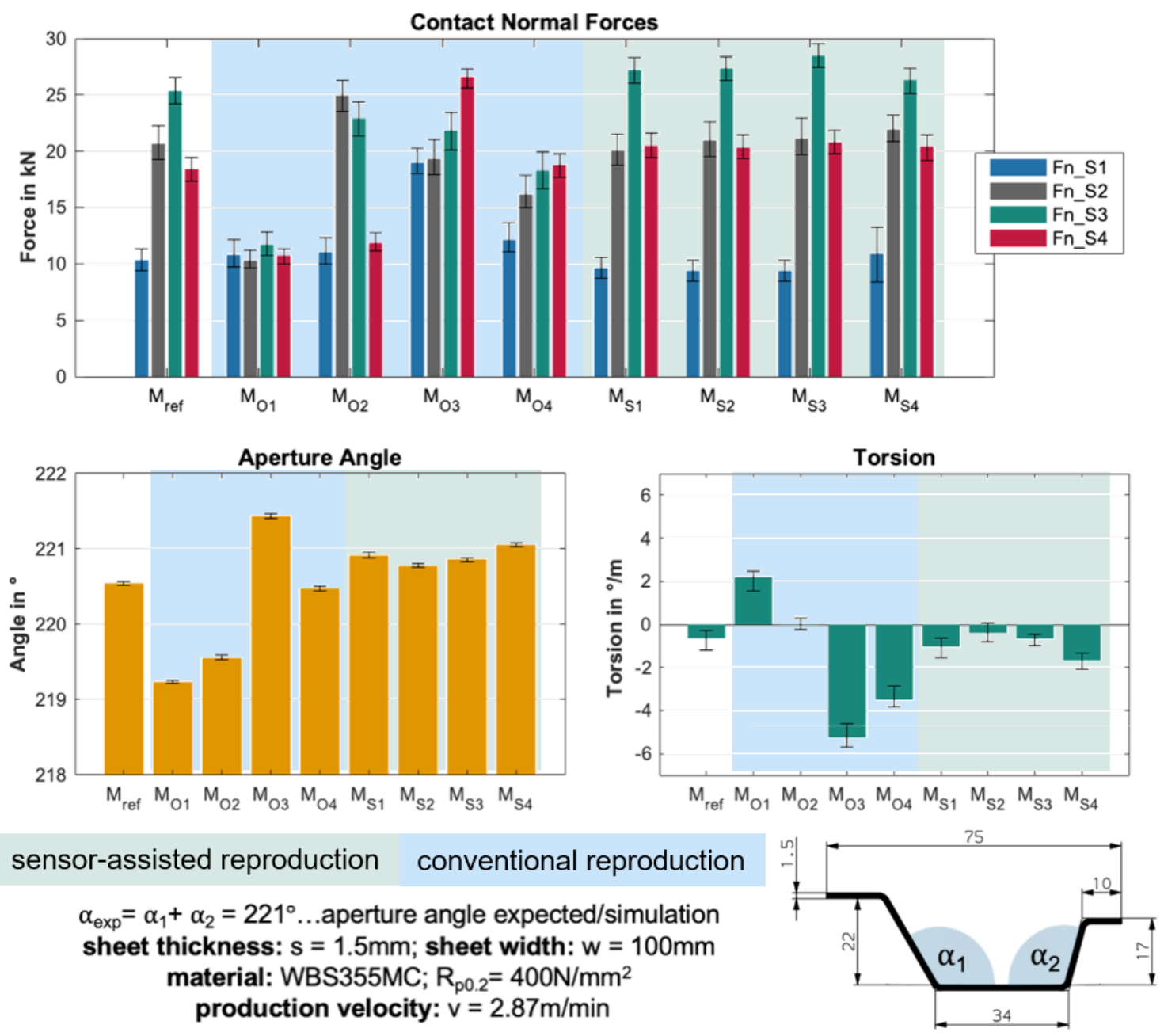

Fig. 6. Sensor equipped roll-forming leading to process stability

Comparing the conventional to the sensor assisted set up process, the scattering of the forces of the sensor-assisted process is way smaller, which leads to smaller variations in the geometry of the profile (see Fig. 6). The study shows the possibility of ensuring reproduction of line adjustments by the geometric state determined before and after 
production in roll forming. Furthermore, the sensor assisted process generates a more stable profile geometry compared to the conventional process in several trials. This leads to the implementation of an inexpensive and robust adjustment processes without the necessity of the integration of sensors in the production line. The realization is implemented by the prediction of occurring forces by FE-simulations and adjusting the machines by geometric characteristics. Hereby, the changeover times of recurring profiles may be dramatically reduced. These experiments pave the way to establish simulation models of the process where integrated accurate tool behavior under load is considered. The digital replication of the machine can then be used to predict the needed geometric characteristics on a roll forming mill to reach the needed force-levels of the individual forming steps. The replica further on can be used to i.e. identify the influence of varying input quality of the metal sheet on the profile geometry.

\section{HEAVY DUTY MILLING}

Sensor integration into milling heads has been investigated in several research works and the already existing systems can be distinguished by way of data transmission. The measured cutting edge forces can be transmitted by a rotor system [80], near field communication [81] or via Bluetooth Low Energy [82].

Especially when milling large steel blocks, sensor integrated tooling systems are of great interest. Forging skin and oxide scale layers (Fig. 7) on the parts, as well as geometrical deviation and scattering material properties effect the process and cause varying conditions that easily effect process stability as shown by Dombovari [83]. Standardizing these stochastic conditions is impossible.
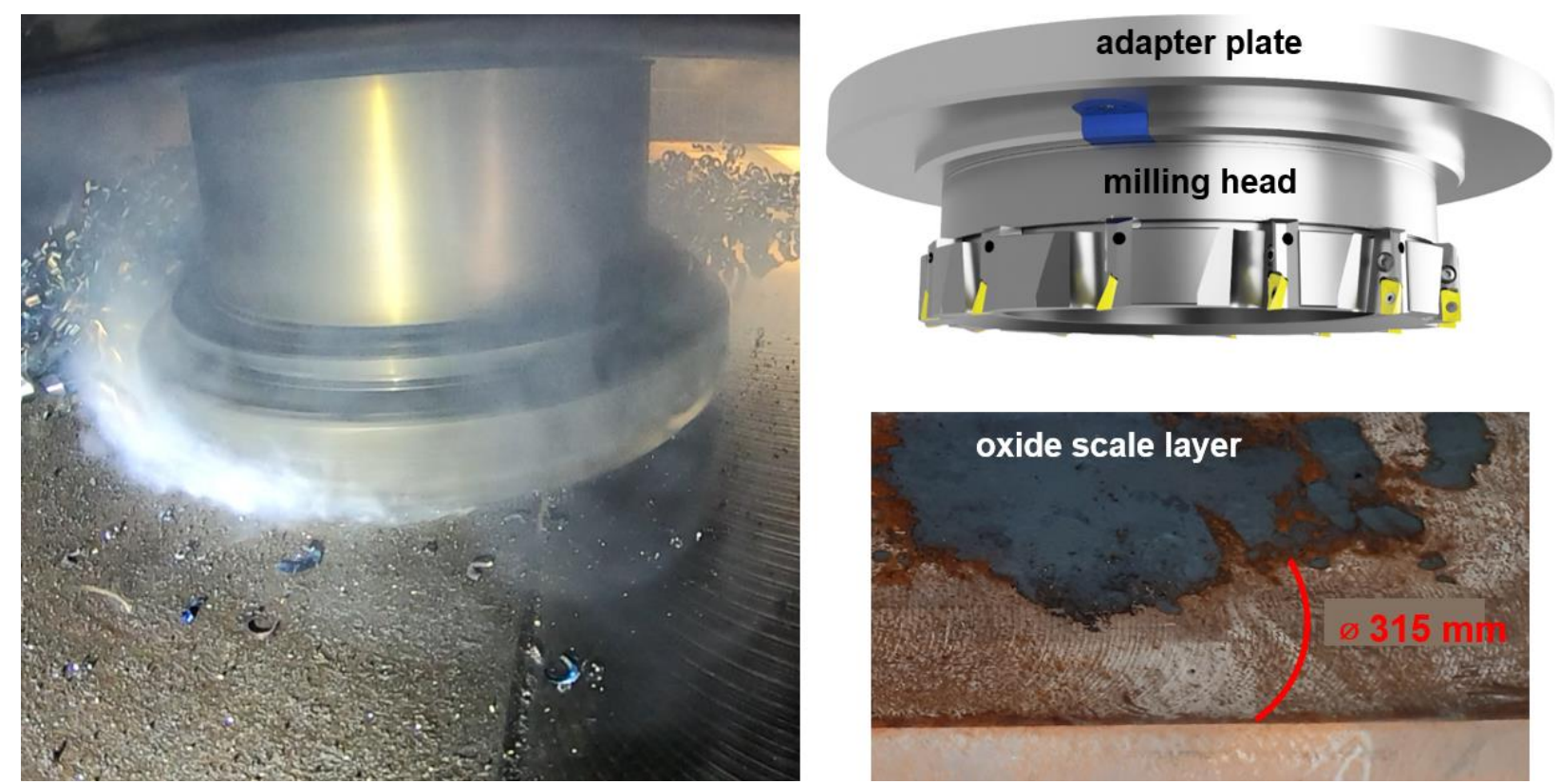

Fig. 7. Milling of big steel blocks with large scale milling heads 
Monitoring real production processes near to the cutting edge by sensor integration into the tooling system raises certain challenges. In this particular use-case, usually no coolant is used for reasons of machinability [84] and so the temperature situation caused by the process has a much larger impact on the durability of sensors and electronics. Therefore, the integrated electronic parts need to be temperature resistant and shock or vibration proof, besides the problem on needed installation space.

Thus, an advanced approach with separated electronic circuits has been developed. The milling head gets equipped with temperature resistant electronics, but the battery, the telemetry system and acceleration measurement can be integrated into the adapter plate between the milling head and spindle. Thus, a new design was created combining the system of the instrumented tool holder with three PCBs (printed circuit boards) into one single PCB for integration into heavy duty milling machines, as shown in Fig. 8. The technology of the instrumented tool holder thus keeps its full functionality enhanced with the additional feature to deliver power supply and a transmission channel for a sensor integrated milling head conductively connected to the adapter plate.

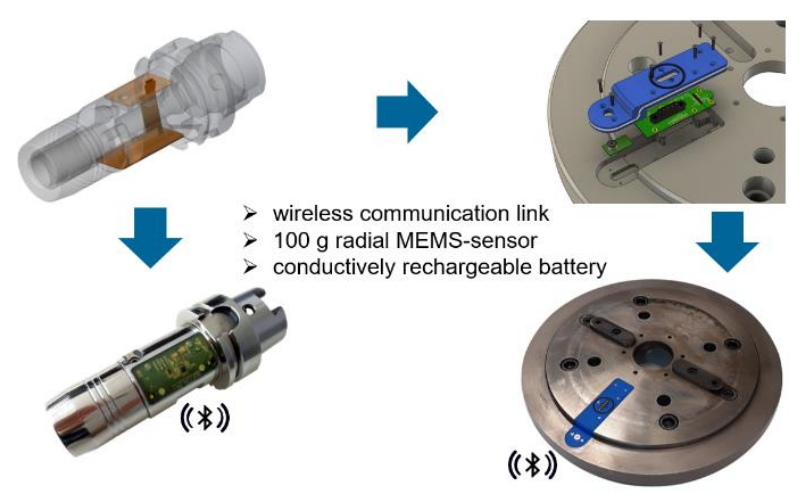

Fig. 8. Sensor integration into tool holder and adapter plate

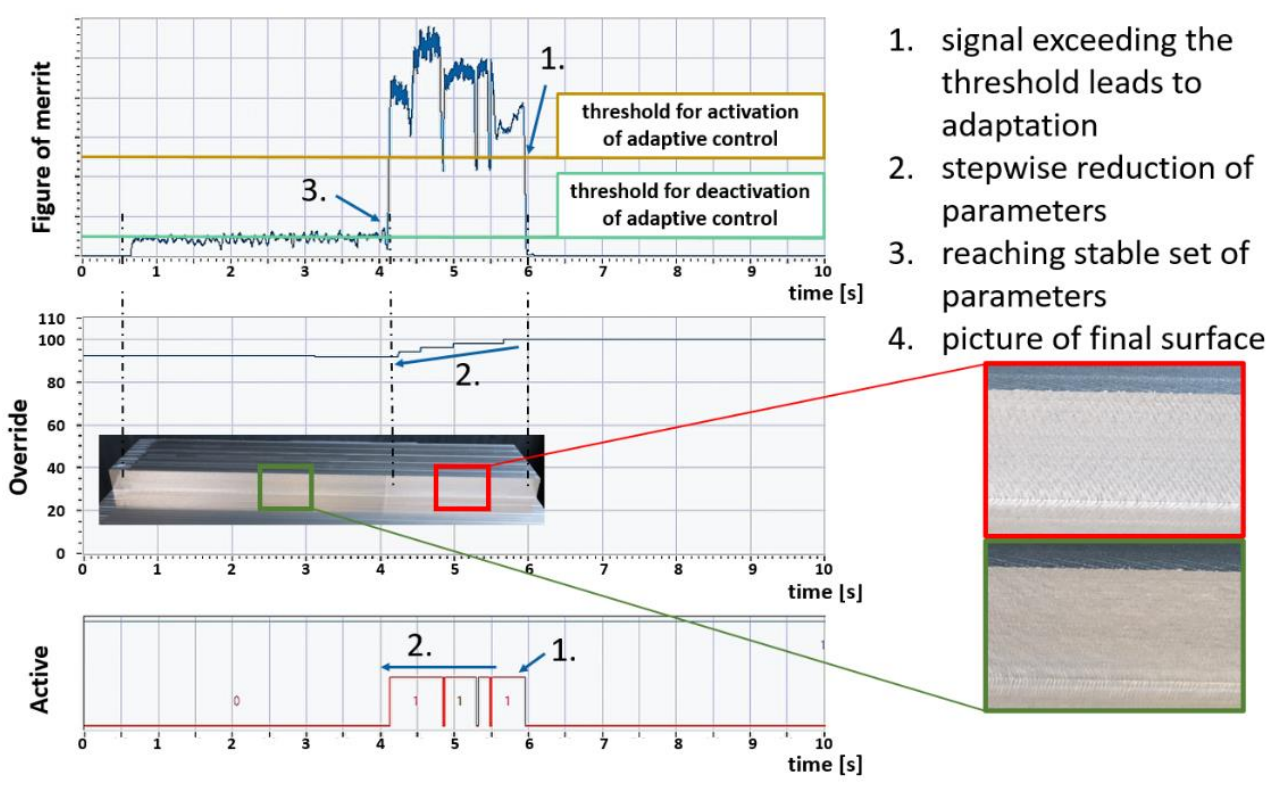

Fig. 9. Stabilizing milling process by real-time control based on sensor data 
This design enables an additional data stream besides the acceleration data using the sensors, which can be located close to the cutting inserts. The sensory adapter plate transmits the gathered data to a stationary transceiver unit via a Bluetooth Low Energy communication channel. This transceiver uses a CAN interface to forward the data to a PC or special signal processing unit. The signal-processing unit provides possibilities for fast data analysis by a pre-defined algorithm and connection to networks or cloud services.

On the one hand, a fast and real-time rule engine sets counter-measures like adaption of spindle speed and feed rate via analog or digital inputs toward the NC-system of the machine tool. On the other hand, provision of data to the manufacturing executing level and sophisticated analyses become possible for not time-critical operations like long-term quality control and CAM based optimization of machining sequences.

A fast response and a specific adaption of the process are required for a feedback loop, so that a control system can cover stochastic process effects. The instrumented tool holder has been proven capable of chatter detection and mitigation $[85,86]$, as well as cutting edge chipping detection [87]. In the case, that a process is classified to be unstable, an automated adaption of spindle speed and feed rate can be applied in the real-time control loop. The usecase in Fig. 9 illustrates the effect of process adaption, however, a rather long distance of insufficient quality processed under unstable conditions remains. This procedure of extraslow process adaptation was chosen for reasons of demonstration and visualization. The adaptation of real production processes is executed much faster, resulting in sufficient quality over the whole work piece.

\section{CONCLUSION}

In this paper, applications and use-cases for sensor integration in tooling systems have been presented and an overview of the sensor data utilization has been provided. In order to achieve an optimum performance of manufacturing processes and complex production systems, time-related information has to be accessible and available from close to the area of the interaction between tool and work piece. Correlating the sensor's data with measurable physical properties of the produced parts is required for each application scenario individually to get a reliable statement or forecast regarding quality. Thus, sensor integration in tool systems enables economically valuable perspectives in different scenarios.

- Serial production processes can be monitored and a forecast of the quality of the products is possible, even if only a black-box model is used. The area of application in injection molding for example, enables to monitor the part quality regarding constant mass through the measurement of mold cavity pressure.

- Complex process models (white-box models) can be validated based on sensor data. Besides digital twins, quality assurance and reducing setup time based on sensor integration in tools have been presented by the use-case of roll forming. In this case, the integration of sensors will lead to deeper understanding of the process models. By their use to predict the processes forces, etc., extensive and thus costly sensor integration may be avoided in the industrial applications. 
- Stochastic effects resulting from inhomogeneous work-piece material quality like oxide layer and forging skin in the case of heavy-duty milling take influence on the results

of manufacturing processes. Real-time data evaluation of sensor information enables autonomous parameter adaption and therefore automated process control based on grey-box models.

Increasingly smaller parts of microelectronic components and the available communication technologies together with reducing prices will lead to even more sensor equipped production processes and components of machine tools. The increased quantity of sensor-based data allows for enhanced functionalities in the field of condition monitoring and quality control. Analysis and evaluating of sensor data will play a more and more crucial role. AI (artificial intelligence) and digital twins or process models, respectively, offer technologies to improve date exploration. A promising aspect can be derived from the use of new time sensitive networking capable technologies, which will allow for more complex evaluation methods and deploy further real-time capabilities.

\section{ACKNOWLEDGEMENTS}

The authors would like to thank Austrian Research Promotion Agency (FFG) for funding projects at TU Wien. Some of the results presented in this paper have been supported by FFG. Furthermore, TU Wien as well as the authors want to express their appreciation and thanks to the Machine Tool Technologies Research Foundation (MTTRF) for supporting the research work. Furthermore, parts of this work have been funded by EIT Manufacturing.

\section{REFERENCES}

[1] NATH C., 2020, Integrated Tool Condition Monitoring Systems and Their Applications: A Comprehensive Review, Procedia Manufacturing, 48, 852-863.

[2] SCHIESSLE E., 2016, Industriesensorik-Sensortechnik und Messwertaufnahme, Vogel Business Media, ISBN 978-3-8343-3341-4, 21-23.

[3] JEMIELNIAK K., 2019, Contemporary Challenges in Tool Condition Monitoring, Journal of Machine Engineering, 2019, 19/1, 48-61.

[4] DIMLA Sr. D.E., LISTER P.M., 1999, On-Line Metal Cutting Tool Condition Monitoring. I: Force and Vibration Analyses, International Journal of Machine Tools \& Manufacture, 40, 739-768.

[5] DWORSCHAK B., ZAISER H., 2014, Competences for Cyber-Physical Systems in Manufacturing - First Findings and Scenarios, Procedia CIRP, 25, 345-350.

[6] YANG X., 2020, Digital Twin for Cutting Tool: Modeling, Application and Service Strategy, Journal of Manufacturing Systems, 58 Part B, 305-312.

[7] GAO R.X., 2008, Injection Molding Process Monitoring Using a Self-Energized Dual-Parameter Sensor, CIRP Annals - Manufacturing Technology, 75, 389-393.

[8] NAKAO M., YODA M., 2003, Locally Controlling Heat Flux for Preventing Micrometre-Order Deformation with Injection Molding of Miniature Products, CIRP, 52/1, 451-454.

[9] MAO T., ZHANG Y., 018, Feature Learning and Process Monitoring of Injection Molding Using ConvolutionDeconvolution Auto Encoders, Computers and Chemical Engineering, 118, 77-90.

[10] MONOSTORI L., 1993, A Step Towards Intelligent Manufacturing: Modelling and Monitoring of Manufacturing Processes through Artificial Neural Networks, CIRP, 42/1, 485-488.

[11] BHATTACHARYYA D., 1986, The Prediction of Roll Load in Cold Roll-Forming, Journal of Mechanical Working Technology, 14, 363-379.

[12] SEDLMAIER A., 2017, Digitalization in Roll Forming Manufacturing, J. Phys., Conf. Ser. 896012038. 
[13] LINDGREN M., 2009, 3D Roll-Forming of Hat-Profile with Variable Depth and Width, $1^{\text {st }}$ International Congress of RollForming, RollFORM Paper 7.

[14] BIDABADI B.S., 2017, Experimental and Numerical Study of Required Torque in the Cold roll Forming of Symmetrical Channel Sections, Journal of Manufacturing Processes, 27, 63-75.

[15] JURKOVIC M., 2015, An Investigation of the Force and Torque at Profile Sheet Metal Rolling-Input Data for the Production System Reengineering, Tehnički Vjesnik, 22/4, 1029-1034.

[16] BECKER M., GROCHE P., 2019, Towards Nonstop Availability in Roll Forming through Digitalization, Wulfsberg J.P., Hintze W., Behrens B.A. (eds), Production at the Leading Edge of Technology, Springer Vieweg, Berlin, Heidelberg, https://doi.org/10.1007/978-3-662-60417-5_22.

[17] LIU X., 2017, Investigation of Forming Parameters on Springback for Ultra High Strength Steel Considering Young's Modulus Variation in Cold Roll Forming, Journal of Manufacturing Processes, 29, 289-297.

[18] TSANG K.S.,2017, Validation of a Finite Element Model of the Cold Roll Forming Process on the Basis of 3D Geometric Accuracy, Procedia Engineering, 207, 1278-1283.

[19] LUO M., LUO H., 2018, A Wireless Instrumented Milling Cutter System with Embedded PVDF Sensors, Mechanical Systems and Signal Processing, 11, 556-568.

[20] MIN S.H., LEE T.H., 2020, Directly Printed Low-Cost Nanoparticle Sensor for Vibration Measurement During Milling Process, MDPI Journal Materials 13, doi:10.3390/ma13132920.

[21] MÖHRING H.C., 2016, Intelligent Tools for Predictive Process Control, Procedia CIRP, 57, 539-544.

[22] CLAUß B., MEINECKE C.R., 2020, Process Monitoring and Impulse Detection in Face Milling Using Capacitive Acceleration Sensors Based on MEMS, Procedia CIRP, 93, 1454-1459.

[23] UEKITA M., TAKAYA Y., 2017, Tool Condition Monitoring for Form Milling of Large Parts by Combining Spindle Motor Current and Acoustic Emission Signals, International Journal of Advanced Manufacturing Technology, 89, 65-75.

[24] SIDDHPURA A., PAUROBALlY R., 2013, A Review of Flank Wear Prediction Methods for Tool Condition Monitoring in a Turning Process, Int. J. Adv. Manuf. Technol., 65, 371-393.

[25] MAYR J., JEDRZEJEWSKI J., 2012, Thermal Issues in Machine Tools, CIRP Annals - Manufacturing Technology, 61, 771-791.

[26] MONOSTORI L., 2014, Cyber-Physical Production Systems: Roots, Expectations and R\&D Challenges, Procedia CIRP, 17, 9-13.

[27] TETI R., 2010, Advanced Monitoring of Machining Operations, CIRP Annals - Manufacturing Technology, 59, 717-739.

[28] SERIN G., 2020, Review of Tool Condition Monitoring in Machining and Opportunities for Deep Learning, The International Journal of Advanced Manufacturing Technology, 109, 953-974.

[29] DENKENA B., 2020, Statistical Approaches for Semi-Supervised Anomaly Detection in Machining, Production Engineering, 14, 385-393.

[30] MÖHRING H.C., 2020, Process Monitoring with a Cyber-Physical Cutting Tool, Procedia CIRP, 93, 1466-1471.

[31] KAUFMANN T., 2020, AI-Based Framework for Deep Learning Applications in Grinding, SAMI 2020 - IEEE 18th World Symposium on Applied Machine Intelligence and Informatics - January 23-25.

[32] CAI Y., 2017, Sensor Data and Information Fusion to Construct Digital-Twins Virtual Machine Tools for CyberPhysical Manufacturing, Procedia Manufacturing, 10, 1031-1042.

[33] QIAOKANG L. 2016, Methods and Research for Multi-Component Cutting Force Sensing Devices and Approaches in Machining, Sensors, 16, 1926.

[34] ZUPERL U., 2011, Neural Control Strategy of Constant Cutting Force System in End Milling, Robotics and Computer-Integrated Manufacturing, 27, 485-493.

[35] TOMIYAMA T., MOYEN F., 2018, Resilient Architecture for Cyber-Physical Production Systems, CIRP Annals - Manufacturing Technology, 67, 161-164.

[36] KUNATH M., WINKLER H., 2018, Integrating the Digital Twin of the Manufacturing System into a Decision Support System for Improving the Order Management Process, Procedia CIRP, 72, 225-231.

[37] PAUKER F., 2018, Centurio.Work - Modular Secure Manufacturing Orchestration, Proceedings of the Dissertation Award and Demonstration, Industrial Track at BPM 2018, CEUR-WS.org, 2018.

[38] IGLESIAS A., 2014, Optimization of Face Milling Operations with Structural Chatter Using a Stability Model Based Process Planning Methodology, Int. J. Adv. Manuf. Technol., 70, 559-571.

[39] MÖHRING H.C., 2018, Material Failure Detection for Intelligent Process Control in CFRP Machining, Procedia CIRP, 77, 387-390.

[40] KAUFMANN T., 2020, AI-based Framework for Deep Learning Applications in Grinding, SAMI 2020 - IEEE $18^{\text {th }}$ World Symposium on Applied Machine Intelligence and Informatics - January 23-25. 
[41] DENKENA B., BOUJNAH H., 2018, Feeling Machines for Online Detection and Compensation of Tool Deflection in Milling, CIRP Annals - Manufacturing Technology, 67, 423-426.

[42] SÖDERBERG R., 2017, Toward a Digital Twin for Real-Time Geometry Assurance in Individualized Production, CIRP Annals - Manufacturing Technology, 66, 137-140.

[43] TONG X., 2019, Real-Time Machining Data Application and Service Based on IMT Digital Twin, Journal of Intelligent Manufacturing, 31, 1113-1132.

[44] OGORODYNK O., MARTINSEN K., 2018, Monitoring and Control for Thermoplastics Injection Molding A Review, Procedia CIRP, 67, 380-385.

[45] AGEYEVA T., HORVATH S., KOVACS J. G., 2019, In-Mold Sensors for Injection Molding: On the Way to Industry 4.0, MDPI, Sensors, 19/16, 3551.

[46] GAO Y., WANG X., 2007, An Effective Warpage Optimization Method in Injection Molding Based on the Kriging Model, The International Journal of Advanced Manufacturing Technology, 37, 953-960.

[47] SUDSAWAT S., SRISEUBSAI W., 2018, Warpage Reduction Through Optimized Process Parameters and Annealed Process of Injection-Molded Plastic Parts, Journal of Mechanical Science and Technology, 32 , 4787-4799.

[48] KC B., FARUK O., AGNELLI J.A.M., LEAO A.L., 2016, Sisal-Glass Fiber Hybrid Biocomposite: Optimization of Injection Molding Parameters Using Taguchi Method for Reducing Shrinkage, Composites Part A, Applied Science and Manufacturing, 83, 152-159.

[49] BARGHASH M., ALKAABNEH F. A., 2014, Shrinkage and Warpage Detailed Analysis and Optimization for the Injection Molding Process Using Multistage Experimental Design, Quality Engineering, 26/3, 319-334.

[50] WANG J., MAO Q., 2012, A Novel Process Control Methodology Based on the PVT Behavior of Polymer for Injection Molding, Advances in Polymer Technology 32/S1, E474-E485.

[51] ZHANG S., DUBAY R., CHAREST M., 2015, A Principal Component Analysis Model-Based Predictive Controller for Controlling Part Warpage in Plastic Injection Molding, Expert Systems with Applications, 42, 2919-2927.

[52] PARK H. S., KUMAR S., 2019, AI Based Injection Molding Process for Consistent Product Quality, Procedia Manufacturing, 28, 102-106.

[53] TEllaECHE A., ARANA R., 2013, Machine Learning Algorithms for Quality Control in Plastic Molding Industry, IEEE 18th Conference on Emerging Technologies \& Factory Automation (ETFA).

[54] CHEN J.Y., YANG K.J., 2018, Online Quality Monitoring of Molten Resin in Injection Molding, International Journal of Heat and Mass Transfer, 122, 681-693.

[55] NIAN S.C., FANG Y.C., HUANG M.S., 2019, In-Mold and Machine Sensing and Feature Extraction for Optimized IC-tray Manufacturing, Polymers, 11/8, 1348.

[56] CHEN J.Y., TSENG C.C., HUANG M.S., 2019, Quality Indexes Design for Online Monitoring Polymer Injection Molding, Advances in Polymer Technology, 419, 1-20.

[57] KUMAR S., PARK H.S., LEE C.M., 2020, Data-Driven Smart Control of Injection Molding Process, CIRP Journal of Manufacturing Science and Technology, 31, 439-449.

[58] PACHER G.A., BERGER G.R., 2014, In-Mold Sensor Concept to Calculate Process-Specific Rheological Properties, AIP Conference Proceedings, 1593, 179.

[59] OGORODYNK O, MARTINSEN K., 2019, Application of Feature Selection Methods for Defining Critical Parameters in Thermoplastics Injection Molding, Procedia CIRP, 81, 110-114.

[60] KOZJEK D., KRALJ D., 2017, A Data-Driven Holistic Approach to Fault Prognostics in a Cyclic Manufacturing Process, Procedia CIRP, 63, 664-669.

[61] CHEN J.Y., LIU C.Y., 2019, Tie-Bar Elongation Based Filling-To-Packing Switchover Control and Prediction of Injection Molding Quality, Polymers, 11/7, 1168.

[62] ISO 20753: Plastics - Test specimens.

[63] YANG M., 2018, Smart Metal Forming with Digital Process and IoT, International Journal of Lightweight Materials and Manufacture, 1, 207-214.

[64] KIM S. Y., 2017, Detection of Abnormal Behavior in Manufacturing Processes Using Bolt Type Piezo-Sensor, Proceedings of the 68th Japanese Joint Conference for the Technology of Plasticity, 181-182.

[65] HAGINO N., 2014, Propagation Behavior of Ultrasonic Wave Around Boundary Surfaces of Workpieces and Dies, Procedia Engineering, 81, 1073-1078.

[66] YANG M., 2003, Data Fusion of Distributed AE Sensors for the Detection of Friction Sources During Press Forming, Journal of Materials Processing Technology, 139, 368-372.

[67] MÜLLER C., 2014, Numerische Abbildung und Validierung von Beanspruchungsgrößen in Rollprofilierprozessen, ISBN 978-3-8440-3255-0.

[68] TRAUB T., MIKS C., GROCHE P., 2017, Force Measurements Supporting the Set-up Process in Roll Forming, Athens: ATINER'S Conference Paper Series, No: MEC2017-2346. 
[69] LINDGREN M., 2007, Experimental Investigations of the Roll Load and Roll Torque When High Strength Steel is Roll Formed, Journal of Materials Processing Technology, 191, 44-47.

[70] LEONHARTSBERBER M., LAMPRECHT M., BLEICHER F., 2020, Influence Parameters on Tool Deflections in Roll Forming, Proceedings of the 31st DAAAM International Symposium, DOI: 10.2507/-st.daaam. proceedings.Xxx.

[71] LAMPRECHT M., 2020, Nonlinear Mechanical Model of the Shaft of a Roll Forming Mill and Parameter Identification, The International Journal of Advanced Manufacturing Technology, https://doi.org/10.1007/s00170020-06412-5.

[72] TRAUB T., 2019, Measures Towards Roll Forming at the Physical Limit of Energy Consumption, The International Journal of Advanced Manufacturing Technology, https://doi.org/10.1007/s00170-019-03992-9.

[73] GROCHE P., 2013, Manufacturing and Use of Novel Sensoric Fasteners for Monitoring Forming Processes, Measurement, 53, 136-144.

[74] LINDGREN M., 2009, Experimental and Computational Investigation of the Roll Forming Process, ISBN 97891-7439-031-5.

[75] NAJAFABADI M.H., 2018, Effect of Forming Parameters on Edge Wrinkling in Cold Roll Forming of Wide profiles, The International Journal of Advanced Manufacturing Technology, https://doi.org/10.1007/s00170-0182885-x.

[76] PARALIKAS J., 2009, Investigation of the Effects of Main Roll-Forming Process Parameters on Quality for a V-Section Profile from AHSS, International Journal of Advanced Manufacturing Technology, 44, $223-237$.

[77] ROSSI B., 2013, Numerical Simulation of the Roll Forming of Thin-Walled Sections and Evaluation of Corner Strength Enhancement, Finite Elements in Analysis and Design, 72, 13-20.

[78] TSANG K.S., 2017, Validation of a Finite Element Model of the Cold Roll Forming Process on the Basis of 3D Geometric Accuracy, Procedia Engineering, 207, 1278-1283.

[79] WIEBENGA J.H., 2013, Product Defect Compensation by Robust Optimization of a Cold Roll Forming Process, Journal of Materials Processing Technology, 213, 978- 986.

[80] TOTIS G., 2010, Development of a Dynamometer for Measuring Individual Cutting Edge Forces in Face Milling, Mechanical Systems and Signal Processing, 24, 1844-1857.

[81] DROSSEL W.-G., 2018, Performance of a New Piezoceramic Thick Film Sensor for Measurement and Control of Cutting Forces During Milling, CIRP Annals - Manufacturing Technology, 67, 45-48.

[82] MAIER W., 2018, Tools 4.0 - Intelligence Starts on the Cutting Edge, Procedia Manufacturing, 24, $299-304$.

[83] DOMOBOVARI Z., 2018, Milling Stability for Slowly Varying Parameters, Procedia CIRP 77, 110-113.

[84] BINXUN L., 2019, Toward Understanding of Metallurgical Behaviours in Dry Machining of Hardened Steel: Phase Transformation and Surface Oxidation, Journal of Material Research and Technology, 8/5, 3811-821.

[85] BLEICHER F., SCHÖRGHOFER P., HABERSOHN C., 2018, In-Process Control with a Sensory Tool Holder to Avoid Chatter, Journal of Machine Engineering, 18/3, 16-27.

[86] SCHÖRGHOFER P., 2019, Using Sensory Tool Holder Data for Optimizing Production Processes, Journal of Machine Engineering, 19/3, 43-55.

[87] BLEICHER F., 2020, Method for Determining Edge Chipping in Milling Based on Tool Holder Vibration Measurements, CIRP, 69, 101-104. 